\title{
Menopausal symptoms and quality of life among Saudi women visiting primary care clinics in Riyadh, Saudi Arabia
}

This article was published in the following Dove Press journal:

International Journal of Women's Health

29 June 2015

Number of times this article has been viewed

\author{
Aida AIDughaither' \\ Hind AIMutairy ${ }^{2}$ \\ Mohammed AlAteeq' \\ 'College of Medicine, King Saud \\ Bin Abdul-Aziz University for \\ Health Sciences, ${ }^{2}$ Department \\ of Family Medicine and PHC, \\ King Abdul-Aziz Medical City, \\ National Guard Health Affairs, \\ Riyadh, Kingdom of Saudi Arabia
}

Objectives: Menopause is associated with somatic, vasomotor, psychological, and sexual complaints that may affect quality of life. We determined the prevalence and severity of menopausal symptoms and their impact on the quality of life among Saudi women visiting primary care centers in Riyadh, Saudi Arabia.

Methods: A cross-sectional study was conducted from October to November 2010. In total, 119 women aged 45-60 years were randomly interviewed using a questionnaire. Participants were divided into three categories: premenopausal $(n=31)$, perimenopausal $(n=49)$, and postmenopausal ( $n=39)$. The Menopause Rating Scale (MRS) assessed the prevalence and severity of eleven menopausal symptoms. Mean scores of menopausal categories were compared for different symptoms.

Results: The mean age at menopause was $48.3 \pm 3$ years (median, 49 years). The symptoms reported to be most prevalent were joint and muscle pain $(80.7 \%)$, physical and mental exhaustion $(64.7 \%)$, and hot flushes and sweating (47.1\%). Somatic and psychological symptoms were highly prevalent in perimenopausal women compared to other groups. The mean overall quality-of-life score was higher in perimenopausal women, while the total MRS score indicated that the symptoms were mild in severity (MRS <9).

Conclusion: The prevalence of menopausal symptoms was comparable to previous studies in Asian women; however, the prevalence of classic symptoms of hot flushes and night sweats was lower than reported in Western studies. Saudi women reported an MRS score indicating milder severity of symptoms, reflecting better quality of life and ability to cope with climacteric symptoms.

Keywords: menopause, Saudi women, Menopause Rating Scale, quality of life

\section{Introduction}

Menopause is a normal physiologic process, defined as the permanent cessation of menses for 12 months or more due to cessation of ovarian hormone production. ${ }^{1,2}$ According to the World Health Organization (WHO) classification, ${ }^{1}$ premenopausal women are those who have experienced regular menstrual bleeding within the last 12 months, perimenopausal women are defined as those women who have experienced irregular menses within the last 12 months or the absence of menstrual bleeding for more than 3 months but less than 12 months, and postmenopausal women are those who have not experienced menstrual bleeding for 12 months or more. Women with iatrogenic menopause are those for whom periods have stopped as a result of medical or surgical intervention, for example, due to chemotherapy or radiation of ovaries, hysterectomy or oophorectomy, or both. The age at natural menopause is between 45 years and 50 years. Early menopause is defined as menopause occurring before the
Correspondence: Mohammed AlAteeq Department of Family Medicine and PHC King Abdul-Aziz Medical City, National Guard Health Affairs, P.O. Box 22490 Riyadh I 1426, Saudi Arabia

Tel +966 I 180 I I I I

ext 46585/46583/49I87

Email malateeq@hotmail.com
International Journal of Women's Health 2015:7 645-653 (c) (i) (5) 2015 AlDughaither et al. This work is published by Dove Medical Press Limited, and licensed under Creative Commons Attribution - Non Commercial (unported, v3.0) BY LC License. The full terms of the License are available at http://creativecommons.org/licenses/by-nc/3.0/. Non-commercial uses of the work are permitted without any further insions beyond the scope of the License are administered by Dove Medical Press Limited. Information on how to request permission may be found at: http://www.dovepress.com/permissions.php 
age of 45 years, while premature menopause occurs before the age of 40 years.

Menopause is a critical period in a woman's life that not only marks the end of reproductive ability but is also associated with multiple physical, vasomotor, psychological, and sexual complaints. There is considerable variation in reporting of menopausal symptoms by women all over the world in different studies. In Latin America, the most reported symptoms included hot flushes (68.9\%), followed by sleeping disturbances (68.4\%). ${ }^{3}$ In Australia, menopause was associated mostly with hot flushes, followed by night sweats. ${ }^{4}$ In Nigeria, joint and muscular discomfort was the most commonly reported symptom (59\%). ${ }^{5}$ In Egypt, the most common symptoms were fatigue, followed by headache. ${ }^{6}$ In contrast, women from most countries in East and Southeast Asia reported joint and muscle pain as the most frequent complaint. ${ }^{7-10}$ Study results in Arab countries are consistent with those performed in most Asian countries. In Jordan, muscle and joint stiffness had a frequency of $89 \% .{ }^{11}$ In the UAE, the most frequent symptoms indicated by menopausal women were pain in the back of the neck or head, followed by aches in muscle and joints. ${ }^{12}$

Age of onset of natural menopause also varies worldwide, with the international range being 44.6-52 years. ${ }^{13}$ In the US, the median age at menopause is 51 years, ${ }^{14}$ while across Europe, age of onset of natural menopause is higher with a mean of 50.7 years and a median of 54.25 years. ${ }^{15}$ Younger ages are observed in Africa, for example, in Morocco, a median age of 48.4 years, and in Alexandria, a mean age \pm standard deviation (SD) of $46.7 \pm 5.44$ years. ${ }^{16,17}$ In South Asia, the mean age of onset of natural menopause in Pakistan is 49.3 years, and in India, the mean age $\pm \mathrm{SD}$ is $45.02 \pm 4.35$ years. ${ }^{18,19}$ In Turkish women, one study showed that median age at menopause was 47 years..$^{20}$ Data from two Gulf countries showed a mean age \pm SD of $48.4 \pm 3.8$ years in the UAE and $48.67 \pm 2.92$ years in Bahrain. ${ }^{12,21}$ In Saudi Arabia, only one study has been performed and showed the mean age at natural menopause to be 48.98 years with a median age of 50 years. ${ }^{22}$

The importance of determining the age at natural menopause is that age is associated with an increased risk of cardiovascular disease, osteoporosis, as well as endometrial and breast cancer. ${ }^{20}$ Moreover, women are expected to live a quarter to a third of their lives in menopause, which makes the quality of life during this period a great concern for women and their treating physician. ${ }^{18,21,23,24}$ The presence of menopausal symptoms significantly reduces the quality of life, and with more severity, worsens the quality of life. ${ }^{7,9,25-27}$
To date, there is limited information about menopause and quality of life in Arab and Gulf countries, and in particular, there are no published studies about menopausal symptoms and quality of life in Saudi Arabia. This study aimed to determine the prevalence and severity of menopausal symptoms among Saudi women, and how menopausal symptoms affect their quality of life.

\section{Methods}

A cross-sectional study was conducted on women visiting a large primary care clinic during the period of October to November 2010. The study included any women aged 45-60 years visiting primary care for gynecological and non-gynecological reasons. Women with early menopause (younger than 45 years) or premature menopause (younger than 40 years), women with medically or surgically induced menopause, women who used hormone replacement therapy, and pregnant or lactating women were excluded. The effective sample size needed to detect a medium effect size (0.15) with $80 \%$ statistical power was found to consist of 119 subjects. $^{28,29}$

The study population consisted of women between 45 years and 60 years of age visiting the Health Care Specialties Clinic, one of the King Abdul-Aziz Medical City Family Medicine Centers, situated in the east of Riyadh, Saudi Arabia, that serves a population of over 150,000. Women were randomly selected (using simple random method) from different areas in the center, for example, from the screening room, and female waiting areas in different clinics. For those who agreed to participate in the study, information was collected by the researchers by face-to-face interview; each interview lasted 5-10 minutes and was conducted using a predesigned questionnaire.

The questionnaire was developed after searching the literature for similar studies, taking into account the study objectives and confounders that might affect the study result like smoking status, exercise, and the presence of chronic disease. It was initially written in English, then translated into Arabic, and then back to English for validation. The completed questionnaire was checked and pretested for clarity and suitability in a small pilot study of ten women. It consisted of three parts: sociodemographic data, menstrual history, and the Menopause Rating Scale (MRS). MRS is a health-related, quality-of-life scale that was developed in the early 1990s to measure severity of aging symptoms and their impact on quality of life. It was initially published in German, and the first translation was from German to English followed by 
translation into other languages, and became internationally accepted. Unfortunately, there was no Arabic version, and for the purpose of this research, English version was used and was translated into Arabic. It consists of eleven items assessing menopausal symptoms divided into three subscales: somatic, psychological, and urogenital. ${ }^{30-32}$ Somatic symptoms include hot flush, heart discomfort, sleeping problem, and muscle and joint pain (items 1-3 and 11, respectively). Psychological symptoms include depressive mood, irritability, anxiety, and physical and mental exhaustion (items 4-7, respectively). Urogenital symptoms include sexual problem, bladder problems, and dryness of vagina (items 8-10, respectively). Each item is graded by subjects from 0 (not present) to 4 ( 1 - mild, 2 - moderate, 3 - severe, 4 - very severe). The total score of each subscale is the sum of item scores contained in that subscale. The higher the score, the worse the quality of life. Total severity score ranged as follows: no or little symptoms $(0-<4)$, mild (4-8), moderate (9-16), and severe (17). ${ }^{30-32}$ Exercise was defined as any physical activity for a duration of 20-30 minutes and was divided into three levels: infrequent (less than 3 times/week), average (3-5 times/week), and more frequent (more than 5 times/ week). In addition, height and weight were measured using the height and weight SECA model 7691321994 Scale made in Germany. The body mass index (BMI) was then calculated using the formula weight/(height) ${ }^{2}$ and reported in kilogram per square meter. The WHO definitions were used to define pre-, peri-, and postmenopausal status in this study. ${ }^{1}$

\section{Statistical analysis}

Data were analyzed using Statistical Package for Social Sciences version 18 (IBM Corp., Armonk, NY, USA). The chi-square test was used to analyze the prevalence of menopausal symptoms in relation to the different menopausal categories indicated above. Analysis of variance and Tukey tests were used to compare the mean of the total MRS score and the somatic, psychological, and urogenital subscale scores for pre-, peri-, and postmenopausal women. The mean scores for those with and without chronic disease were compared using Student's $t$-test. All results were declared statistically significant with a $P$-value $<0.05$.

\section{Ethical considerations}

This study was approved by the King Abdullah International Medical Research Centre. Verbal consent was obtained from each participant, and all data were kept confidential and used for research purposes only.

\section{Results}

\section{Characteristics of the study population}

The study included 119 Saudi women aged 45-60 years with a mean age of $49.7 \pm 3.5$ years. Thirty-one women $(26.1 \%)$ were premenopausal, $49(41.2 \%)$ were perimenopausal, and 39 (32.8\%) were postmenopausal. Most women were married (77.3\%), 83.2\% illiterate, 97.5\% housewives, $100 \%$ parous, and $98.3 \%$ were nonsmokers. Forty-three percent of women were overweight, while $36.1 \%$ were of normal weight. In this study, age at natural menopause was found to be $48.3 \pm 3$ years with a median of 49 years (Tables 1 and 2).

\section{Menopausal symptoms experienced}

The three symptoms reported to be most prevalent included joint and muscle pain (80.7\%), physical and mental exhaustion (64.7\%), and hot flushes and sweating (47.1\%). Of those who reported muscle and joint discomfort, more than half

Table I Baseline characteristic of participants

\begin{tabular}{|c|c|}
\hline Characteristics & $n=119$ \\
\hline Age (years), mean $\pm S D$ & $49.7 \pm 3.5$ \\
\hline \multicolumn{2}{|l|}{ BMI, n (\%) } \\
\hline Underweight & $2(1.7)$ \\
\hline Normal weight & $43(36.1)$ \\
\hline Overweight & $50(42)$ \\
\hline Obese & $24(20.2)$ \\
\hline \multicolumn{2}{|l|}{ Marital status, n (\%) } \\
\hline Single & 0 \\
\hline Married & $92(77.3)$ \\
\hline Widow & $24(20.2)$ \\
\hline Separated & $3(2.5)$ \\
\hline \multicolumn{2}{|l|}{ Educational level, n (\%) } \\
\hline Illiterate & $99(83.2)$ \\
\hline Primary school & 14 (I I.8) \\
\hline Intermediate school & $5(4.2)$ \\
\hline High school & $\mathrm{I}(0.8)$ \\
\hline \multicolumn{2}{|l|}{ Occupation, n (\%) } \\
\hline Housewife & $116(97.5)$ \\
\hline Working & $2(1.7)$ \\
\hline Retired & I $(0.8)$ \\
\hline \multicolumn{2}{|l|}{ Parity, n (\%) } \\
\hline Parous & $119(100)$ \\
\hline \multicolumn{2}{|l|}{ Smoking, n (\%) } \\
\hline Never & 117 (98.3) \\
\hline Past smoker & $\mathrm{I}(0.8)$ \\
\hline Current smoker & $\mathrm{I}(0.8)$ \\
\hline \multicolumn{2}{|c|}{ Exercise (times/week), n (\%) } \\
\hline$<3$ & $106(89.1)$ \\
\hline $3-5$ & $4(3.4)$ \\
\hline$>5$ & $9(7.6)$ \\
\hline
\end{tabular}

Abbreviations: SD, standard deviation; BMI, body mass index. 
Table 2 Characteristics of participants according to menopausal status ( $n=\mid 19)$

\begin{tabular}{|c|c|c|c|}
\hline \multirow[t]{2}{*}{ Characteristics } & \multicolumn{3}{|l|}{ Menopausal status } \\
\hline & Premenopause, $\mathbf{n}$ & Perimenopause, $\mathbf{n}$ & Postmenopause, $\mathbf{n}$ \\
\hline Total no (\%) & $31(26.1)$ & $49(4 I .2)$ & $39(32.8)$ \\
\hline Age (years), mean $\pm S D$ & $46.55 \pm 2.095$ & $49.65 \pm 2.705$ & $52.31 \pm 3.381$ \\
\hline \multicolumn{4}{|l|}{ BMI, n (\%) } \\
\hline Underweight & $\mathrm{I}(0.8)$ & $0(0)$ & $\mathrm{I}(0.8)$ \\
\hline Normal weight & $14(11.8)$ & $17(14.3)$ & $12(10.1)$ \\
\hline Overweight & II (9.2) & $22(18.5)$ & $17(14.3)$ \\
\hline Obese & $5(4.2)$ & $10(8.4)$ & $9(7.6)$ \\
\hline \multicolumn{4}{|l|}{ Marital status, n (\%) } \\
\hline Single & $0(0)$ & $0(0)$ & $0(0)$ \\
\hline Married & $25(2 \mathrm{I})$ & $38(31.9)$ & $29(24.4)$ \\
\hline Widow & $5(4.2)$ & II (9.2) & $8(6.7)$ \\
\hline Separated & $\mathrm{I}(0.8)$ & $0(0)$ & $2(1.7)$ \\
\hline \multicolumn{4}{|l|}{ Educational level, n (\%) } \\
\hline Illiterate & $25(2 \mathrm{I})$ & $38(31.9)$ & $36(30.3)$ \\
\hline Primary school & $4(3.4)$ & $8(6.7)$ & $2(1.7)$ \\
\hline Intermediate school & $2(1.7)$ & $2(1.7)$ & $\mathrm{I}(0.8)$ \\
\hline High school & $0(0)$ & $\mathrm{I}(0.8)$ & $0(0)$ \\
\hline \multicolumn{4}{|l|}{ Occupation, n (\%) } \\
\hline Housewife & $29(24.4)$ & $48(40.3)$ & $39(32.8)$ \\
\hline Working & $\mathrm{I}(0.8)$ & $\mathrm{I}(0.8)$ & $0(0)$ \\
\hline Retired & $\mathrm{I}(0.8)$ & $0(0)$ & $0(0)$ \\
\hline \multicolumn{4}{|l|}{ Parity, n (\%) } \\
\hline Parous & $31(26.1)$ & $49(4 I .2)$ & $39(32.8)$ \\
\hline \multicolumn{4}{|l|}{ Smoking, n (\%) } \\
\hline Never & $31(26.1)$ & $48(40.3)$ & $38(31.9)$ \\
\hline Past smoker & $0(0)$ & $\mathrm{I}(0.8)$ & $0(0)$ \\
\hline Current smoker & $0(0)$ & $0(0)$ & $\mathrm{I}(0.8)$ \\
\hline \multicolumn{4}{|c|}{ Exercise (times/week), n (\%) } \\
\hline$<3$ & $30(25.2)$ & $40(33.6)$ & $36(30.3)$ \\
\hline $3-5$ & $0(0)$ & $4(3.4)$ & $0(0)$ \\
\hline$>5$ & $\mathrm{I}(0.8)$ & $5(4.2)$ & $3(2.5)$ \\
\hline
\end{tabular}

Abbreviations: SD, standard deviation; BMI, body mass index.

(51.3\%) considered it to be moderate to very severe, while $31.1 \%$ of those with hot flushes and sweating considered the discomfort as moderate to very severe (Table 3).

The prevalence of menopausal symptoms according to menopausal status is shown in Table 4. Most of the somatic subscale symptoms (apart from sleep disturbances) were prevalent in the perimenopausal group. Although hot flushes, heart discomfort, and joint and muscular discomfort were highly prevalent in the perimenopausal group, only the prevalence of hot flushes was found to be statistically significantly different between pre- and perimenopausal women $(P<0.05)$. The same was true for the psychological subscale: depression, anxiety, physical and mental exhaustion were all prevalent in the perimenopausal group, but none of these symptoms were statistically significant during menopausal transition. In the urogenital subscale, bladder problems were statistically significantly higher in perimenopausal women compared to the premenopausal group $(P=0.012)$.

\section{Quality of life}

Mean total score and subscale scores of the MRS in relation to menopausal categories are shown in Table 5. The mean total score was higher in the perimenopausal group (8.4 \pm 5.3$)$. Perimenopausal women had higher somatic (4.2 \pm 2.5$)$ and

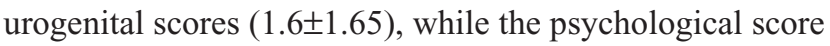
was higher in postmenopausal women (2.74 \pm 2.6$)$, although this result was not statistically significant.

\section{Quality-of-life changes with aging}

The mean total MRS score for the different age groups is shown in Figure 1. Premenopausal women have a constant 
Table 3 Prevalence of menopausal symptoms according to Menopause Rating Scale ( $n=1$ |9)

\begin{tabular}{lll}
\hline $\begin{array}{l}\text { Menopausal } \\
\text { symptoms }\end{array}$ & $\begin{array}{l}\text { \% with } \\
\text { symptoms }\end{array}$ & $\begin{array}{l}\text { \% with moderate } \\
\text { to very severe }\end{array}$ \\
\hline I: hot flush, sweating & 47.1 & 31.1 \\
2: heart discomfort & 35.3 & 10.1 \\
3: sleep problems & 26.1 & 14.3 \\
4: depressive mood & 29.4 & 12.6 \\
5: irritability & 28.6 & 11.8 \\
6: anxiety & 31.1 & 11.8 \\
7: physical and mental exhaustion & 64.7 & 27.7 \\
8: sexual problems & 24.4 & 19.3 \\
9: bladder problems & 30.3 & 12.6 \\
10: vaginal dryness & 31.1 & 14.3 \\
II: joint and muscular discomfort & 80.7 & 51.3 \\
\hline
\end{tabular}

score with increasing age; however, in the perimenopausal group, older age is associated with an increase in high mean total score up to the age of 50 years, and then, the score declined thereafter. The same is also observed with the postmenopausal group; increasing age is associated with an increase in the total MRS score up to the age of 53 years, which then declined with older age.

\section{Effect of smoking, exercise, and BMI on the total MRS score of quality of life}

Smoking had no effect on the quality-of-life score. Women who exercised on average 3-5 times/week had a lower score than those who exercised less frequently ( $<3$ times/week) or more frequently ( $>5$ times/week; Table 6$)$. Women with a normal BMI had a significantly lower total score $(P=0.017)$ compared to underweight, overweight, or obese women.
Moreover, somatic $(P \leq 0.007)$ and psychological subscale $(P \leq 0.008)$ scores were significantly lower in women with normal BMI (Table 7).

\section{Discussion}

The present study investigated the prevalence of menopausal symptoms and health-related quality of life in a sample of Saudi women aged 45-60 years. Our results showed that the most reported symptoms were joint and muscular discomfort, physical and mental exhaustion, and hot flushes. This is consistent with study results in most Asian populations. ${ }^{7-10}$ Interestingly, in a recent study in Pakistan, Nisar and Sohoo ${ }^{18}$ showed almost similar percentages of reported symptoms as in our study: $80.1 \%$ of women reported joint and muscular discomfort as the most prevalent symptom, followed by fatigue and stress $(67.1 \%) .{ }^{18}$

The classical menopausal symptoms, hot flushes and night sweating, were noted to be less prevalent in our study than in the Western population. Generally, it was found that the prevalence of hot flushes in the West ranged from $40 \%$ to $60 \%$ among perimenopausal and $8 \%$ to $80 \%$ among postmenopausal women. ${ }^{33}$ This difference may be explained by the local climate in Riyadh, which is extremely hot and reduces women's sensitivity to elevated temperatures, or alternatively, women may attribute the warming sensation of hot flushes to ambient weather. ${ }^{34}$ Moreover, racial/ethnic background affects the prevalence of the symptoms all over the world. This is supported by the Study of Women's Health Across the Nation (SWAN) study. ${ }^{35-37}$ This was a large longitudinal, multicenter, multiethnic, community

Table 4 Prevalence of menopausal symptoms according to menopausal status ( $n=119)$

\begin{tabular}{|c|c|c|c|c|c|}
\hline \multirow[t]{3}{*}{ Subscale } & \multicolumn{5}{|c|}{ Prevalence (\%) of menopausal symptoms } \\
\hline & \multicolumn{3}{|c|}{ Menopausal status } & \multicolumn{2}{|l|}{$P$-value } \\
\hline & Pre $(n=3 I)$ & Peri $(n=49)$ & Post $(n=39)$ & Pre vs peri & Pre vs post \\
\hline \multicolumn{6}{|l|}{ Somatic } \\
\hline I: hot flush, sweating & 7.6 & 24.4 & I5. I & 0.009 & 0.144 \\
\hline 2: heart & 8.4 & 16.8 & 10.1 & $0.44 I$ & 0.894 \\
\hline 3: sleep problem discomfort & 7.6 & 8.4 & 10.1 & 0.377 & 0.875 \\
\hline II: joint and muscle & 20.2 & 36.1 & 24.4 & 0.222 & 0.767 \\
\hline \multicolumn{6}{|l|}{ Psychological } \\
\hline 4: depressive mood & 4.2 & 13.4 & 11.8 & 0.102 & 0.065 \\
\hline 5: irritability & 5 & 10.9 & 12.6 & 0.462 & 0.083 \\
\hline 6: anxiety & 5 & 14.3 & 11.8 & 0.14 & 0.128 \\
\hline 7: physical and mental exhaustion & 14.3 & 28.6 & 21.8 & 0.187 & 0.313 \\
\hline \multicolumn{6}{|l|}{ Urogenital } \\
\hline 8: sexual problems & 6.7 & 7.6 & 10.1 & 0.428 & 0.648 \\
\hline 9: bladder problem & 5 & 19.3 & 5.9 & 0.012 & $0.88 \mathrm{I}$ \\
\hline 10: vaginal dryness & 7.6 & 13.4 & 10.1 & 0.734 & 0.875 \\
\hline
\end{tabular}

Note: Bold values represent statistically significant values. 
Table 5 Mean scores of MRS according to menopausal status

\begin{tabular}{|c|c|c|c|c|c|}
\hline \multirow[t]{2}{*}{ Subscale } & \multicolumn{3}{|c|}{ Menopausal status } & \multicolumn{2}{|l|}{$\boldsymbol{P}$-value ${ }^{* *}$} \\
\hline & Pre $(n=31)$ & Peri $(n=49)$ & Post $(n=39)$ & Pre vs peri & Pre vs post \\
\hline Somatic & $3.06 \pm 2.84$ & $4.2 \pm 2.5$ & $3.13 \pm 2.52$ & 0.15 & 0.99 \\
\hline Psychological & $\mathrm{I} .8 \mathrm{I} \pm 2.37$ & $2.67 \pm 2.77$ & $2.74 \pm 2.60$ & 0.32 & 0.3 \\
\hline Urogenital & $1.55 \pm 2.25$ & $1.57 \pm 1.65$ & $1.49 \pm 1.83$ & 0.99 & 0.99 \\
\hline Total score & $6.42 \pm 6.33$ & $8.4 \pm 5.34$ & $7.36 \pm 5.45$ & 0.27 & 0.77 \\
\hline
\end{tabular}

Notes: Results are presented as mean \pm SD. $P$-value is significant when $<0.05$. **P-values were based on post hoc test.

Abbreviations: MRS, Menopause Rating Scale; SD, standard deviation; ANOVA, analysis of variance.

study that included non-Hispanic Caucasians, African Americans, Hispanics, Japanese Americans, and Chinese Americans.

The prevalence of combined hot flushes and night sweating was lowest among women of Japanese (18\%) origin, while increasing among Chinese (21\%), Caucasian (31\%), Hispanic (35\%), and African Americans (46\%). Moreover, it has been hypothesized that diet plays a role in the type and severity of menopausal symptoms. It was found that a diet high in phytoestrogens protects against vasomotor symptoms. Phytoestrogens are present in high quantities in soya products. A typical Japanese diet contains high amounts of soya, and this led to the observation that soya may be associated with a decrease in vasomotor symptoms. A study by Nagata et al ${ }^{13}$ provided evidence leading to this conclusion. However, the beneficial effects of phytoestrogens are still a controversial issue. It must be considered however that apart from climatic, racial/ethnic, or dietary effects on

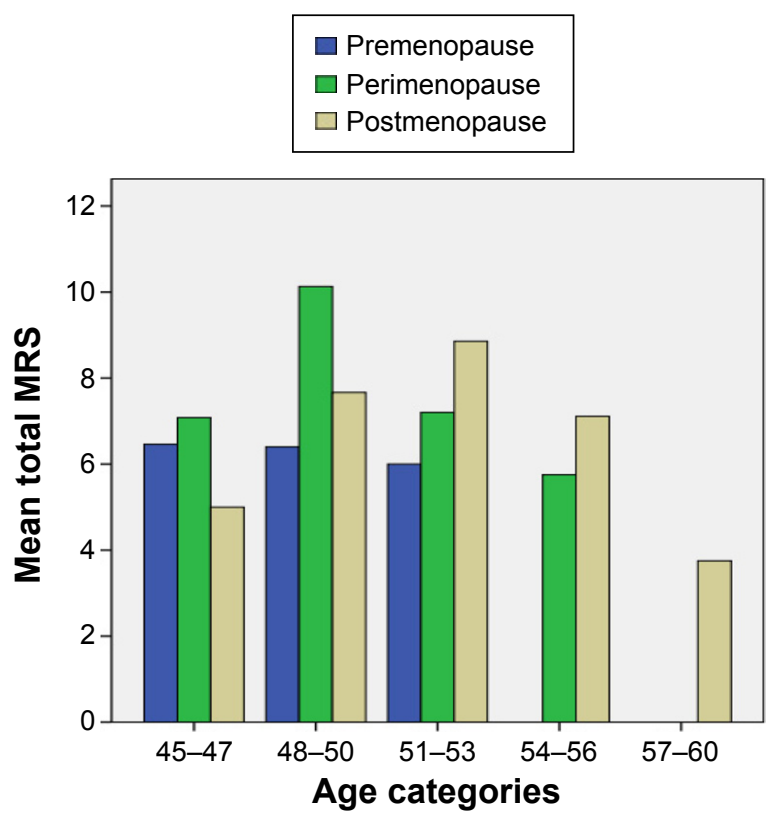

Figure I Quality-of-life changes with aging. Abbreviation: MRS, Menopause Rating Scale. the type and prevalence of menopausal symptoms, other factors should also be considered in the interpretation of data from different studies, including the different methodologies adopted, sample size, age group included, and the characteristics of participants, such as education and social background.

With regard to the menopausal groups evaluated, we found in our study that perimenopausal women reported a higher frequency of somatic and psychological symptoms compared to other groups. This could be explained by fluctuating levels of hormones, such as follicular-stimulating hormone and estrogen, which occur during menopausal transition. Although these symptoms tend to decline in postmenopausal women, they are still higher than in premenopausal women. This is very similar to the results reported in the study of Nisar and Sohoo. ${ }^{18}$ One recent study performed on Jordanian women showed that a higher frequency of symptoms occurred in the perimenopausal women compared to premenopausal and postmenopausal women. ${ }^{39}$ In contrast, the study by Chedraui et $\mathrm{al}^{40}$ in Ecuador found that there is a significant increasing trend in the rate of menopausal symptoms from pre- to postmenopausal women; this also might reflect the influence of different racial/ethnic groups on menopausal symptoms.

The quality of life, in our study, was measured by the MRS. The more severe the symptoms, the higher the MRS

Table 6 Relationship between smoking and exercise and MRS quality-of-life score

\begin{tabular}{lll}
\hline & Mean total score & $P$-values \\
\hline Smoking & & \\
$\quad$ Current & 4 & 0.82 \\
Past & 7 & \\
$\quad$ Never & $7.59 \pm 5.71$ & \\
Exercise (times/week) & & \\
$>5$ & $9.44 \pm 5.66$ & 0.49 \\
$3-5$ & $5.75 \pm 3.86$ & \\
$<3$ & $7.46 \pm 5.55$ & \\
\hline
\end{tabular}

Note: $P$-values were based on ANOVA.

Abbreviations: MRS, Menopause Rating Scale; ANOVA, analysis of variance. 
Table 7 Effect of BMI on MRS quality-of-life scores

\begin{tabular}{|c|c|c|c|c|c|c|}
\hline \multirow[t]{2}{*}{ Subscales } & \multicolumn{4}{|l|}{ BMI } & \multirow[t]{2}{*}{ P-values* } & \multirow[t]{2}{*}{ Significant difference ${ }^{* *}$} \\
\hline & Underweight & Normal weight & Overweight & Obese & & \\
\hline Somatic & $5.5 \pm 7.78$ & $2.47 \pm 2.04$ & $4.10 \pm 2.61$ & $4.17 \pm 2.7 \mid$ & 0.007 & $\begin{array}{l}\text { Normal weight vs overweight, } \\
P \text {-value }=0.013 \\
\text { Normal weight vs obesity, } \\
P \text {-value }=0.047\end{array}$ \\
\hline Psychological & $6.5 \pm 7.78$ & $1.58 \pm 1.694$ & $2.96 \pm 2.85$ & $2.7 I \pm 2.59$ & 0.008 & $\begin{array}{l}\text { Normal weight vs underweight, } \\
P \text {-value }=0.04 \\
\text { Normal weight vs overweight, } \\
P \text {-value }=0.048\end{array}$ \\
\hline Urogenital & $\mathrm{I} \pm \mathrm{I} .4 \mathrm{I}$ & $1.49 \pm 1.91$ & $1.72 \pm 1.89$ & $1.29 \pm 1.80$ & 0.783 & - \\
\hline Total score & $13 \pm 16.97$ & $5.53 \pm 4.43$ & $8.78 \pm 5.94$ & $8.17 \pm 5.12$ & 0.017 & $\begin{array}{l}\text { Normal weight vs overweight, } \\
P \text {-value }=0.027\end{array}$ \\
\hline
\end{tabular}

Notes: Results are presented as mean \pm SD. All $P$-values are significant if $<0.05$. $* P$-values were based on ANOVA. $* * P$-values were based on post hoc tests. Bold values represent statistically significant values.

Abbreviations: BMI, body mass index; MRS, Menopause Rating Scale; SD, standard deviation; ANOVA, analysis of variance.

score and the worse the quality of life. In our study, the total MRS score was higher in the perimenopausal group compared to the postmenopausal and premenopausal groups. Overall, these MRS scores indicate a milder severity. This is different from the severity of symptoms reported in the study of Nisar and Sohoo. ${ }^{18}$ The authors reported a higher score indicating a moderate severity (9-16) of symptoms. The total MRS score for perimenopausal women was higher than that found in our study (15.2 \pm 7.3$)$, and likewise for postmenopausal (14.4 \pm 7.8$)$ and premenopausal (11.9 \pm 6.5$)$ women.

Moreover, no relation was found between smoking or exercise and the mean total MRS score. This could be explained by the fact that most of the participants included reported the same level of exercise, and almost all women were nonsmokers.

The mean age at menopause onset of the Saudi women attending primary care centers in Riyadh in our study was $48.3 \pm 3$ with a median age of 49 years. Only one other study addressed the mean age at menopause of Saudi Arabian women and reported a mean age of 48.9 years with a median of 50 years, which are very similar to that of our cohort. ${ }^{22}$ Data from two Gulf countries, the UAE and Bahrain, gave similar results: in the UAE, the mean age was $48.4 \pm 3.8$ years, and in Bahrain, it was $48.67 \pm 2.9$ years. This age is associated with an increased risk of cardiovascular disease, osteoporosis, and endometrial and breast cancer. ${ }^{20}$ The timing of the onset of menopause depends on several factors including smoking, parity level, and BMI. Smoking in the literature is consistently associated with an earlier age of onset of menopause..$^{14,41-43}$ Nulliparity is also associated with an early onset of menopause ${ }^{15,43}$ as parous women have an anovulatory period that delays menopause. In addition, a low BMI has also been associated with early menopause, ${ }^{42,43}$ and this may be due to higher levels of stored estrogen in the peripheral tissues of obese women. In our study, there was no association between smoking, parity, or BMI and the age at menopause. However, this observation could be explained by the composition of our cohort in that there was only one current smoker and one past smoker, and also, parity was high for all women; thus, the relation cannot be studied accurately.

In conclusion, the classical menopausal symptoms of hot flushes and sweating were less prevalent compared to studies in the West. The menopausal symptoms found to be most prevalent using MRS in this study were joint and muscle discomfort, physical and mental exhaustion, and hot flushes. Saudi women report milder severity scores of MRS, which reflect better quality of life and their ability to cope with some menopausal symptoms.

In the future, multicenter studies involving Saudi women with a larger sample population and different geographic locations are recommended to have more complete data on menopausal symptoms and quality of life during menopausal transition. The sample in this study may not represent the entire female population in Saudi Arabia, since it was carried out in one health facility that serves only National Guard soldiers and their dependents. This population was distinct and shared certain characteristics, and this was not related to the sampling methodology. Most of the females had low level of literacy, similar levels of physical activity, and were nonsmokers. The information in MRS is a subjective more than an objective assessment. In addition, some information taken during patients' interview might be subjected to recall bias, which might affect median age at onset of menopause. 


\section{Disclosure}

The authors report no conflicts of interest in this work.

\section{References}

1. World Health Organization. Research on Menopause in the 1990s: Report of WHO Scientific Group. WHO Technical Report Series 866. Geneva: World Health Organization; 1996.

2. Solues MR, Sherman S, Parrott E, Rebar R, Santoro N. Executive summary, stages of reproductive aging workshop (STRAW). Fertil Steril. 2001;8:874-878.

3. Chedraui P, San Miguel G, Avila C. Quality of life impairment during female menopausal transition is related to personal and partner factors. Gynecol Endocrinol. 2009;25(2):130-135.

4. Berecki-Giosolf J, Begum N, Dobson AJ. Symptoms reported by women in midlife: menopausal transition or aging? Menopause. 2009;16(5): 1021-1029.

5. Funmilola MO, Taiwo O. Experience of menopausal symptoms by women in an urban community in Ibadan, Nigeria. Menopause. 2009; 16(4):822-830.

6. Loutfy I, Abdel Aziz F, Dabbous N. Women's perception and experience of menopause: a community-based study in Alexandria, Egypt. East Mediterr Health J. 2006;12(2):93-106.

7. Peeyananjarassri K, Cheewadhanaraks S, Hubbard M, Manga RZ, Eden J. Menopausal symptoms in a hospital-based sample of women in southern Thailand. Climacteric. 2006;9:23-29.

8. Bairy L, Adiga S, Bhat P, Bhat R. Prevalence of menopausal symptoms and quality of life after menopause in women from South India. Aust N Z J Obstet Gynaecol. 2009;49(1):106-109.

9. Waidysakera H, Wijewardena K, Lindmark G, Naessen T. Menopausal symptoms and quality of life during the menopausal transition in Sri Lankan women. Menopause. 2009;16(1):164-170.

10. Ayranci U, Orsal O, Orsal O, Arslan G, Emekisiz DF. Menopause status and attitudes in Turkish midlife female population: an epidemiological study. BMC Womens Health. 2010;10:1

11. Shakhatreh F, Mas'ad D. Menopausal symptoms and health problems of women aged 50-65 years in Southern Jordan. Climacteric. 2006;9: 305-311.

12. Bener A, Rizk DE, Shaheen H, Micallef R, Osman N, Dunn EV. Measurement-specific quality-of-life satisfaction during menopause in an Arabian Gulf country. Climacteric. 2000;3(1):43-49.

13. Thomas F, Renaud F, Benefice E, Meeus T, Guegan J. International variability of age at menarche and menopause: pattern and main determinant. Hum Biol. 2001;73:271-290.

14. Fleming L, Levis S, LebBlanc W, et al. Earlier age at menopause, work and tobacco smoke exposure. Menopause. 2008;15(6):1103-1108.

15. Dravta J, Real F, Schindler C, et al. Is age at menopause increasing across Europe? Results on age at menopause and determinants from two population-based studies. Menopause. 2009;16(2):385-394.

16. Reynols RF, Obermeyer CM. Correlates of age at natural menopause in Morocco. Ann Hum Biol. 2003;30:97-108.

17. Hidayet NM, Sharaf SA, Aref SR, Tawfik TA, Moubarak II. Correlates of age at natural menopause: a community-based study in Alexandria. East Mediterr Health J. 1999;5:307-319.

18. Nisar N, Sohoo NA. Severity of menopausal symptoms and quality of life at different status of menopause: a community based survey from rural sindah, Pakistan. Int J Collab Res Intern Med Public Health. 2010; 2(5):118-130.

19. Kapur P, Sinha B, Pereira B. Measuring climacteric symptoms and age at natural menopause in an Indian population using the Greene climacteric scale. Menopause. 2009;16(2):378-384.

20. Vehid S, Aran S, Koksal S, Isiloglu H, Senocak M. The prevalence and the age at the onset of menopause in Turkish women in rural area. Saudi Med J. 2006;27(9):1381-1386.
21. Jassim G, Al-Shaboul Q. Attitude of Bahraini women towards the menopause: implication for health policy. Maturitas. 2008;59:358-372.

22. Greer W, Sandridge A, Chehabeddine R. The frequency distribution of age at natural menopause Saudi Arabian women. Maturitas. 2003;46: 263-272.

23. Jahanfar SH, Abdul Rahim B, Shah Reza B, Nor A, Sharifa N, Siti A. Age of menopause and menopausal symptoms among Malaysian women who referred to Health Clinic in Malaysia. Shiraz E-Med J. 2006; 7(3):1-9.

24. Chen Y, LIN S, Wei Y, Gao H, WU Z. Menopause-specific quality of life satisfaction in community-dwelling menopausal women in china. Gynecol Endocrinol. 2007;23(3):166-172.

25. William R, Levine K, Kalini L, Lewis J, Clark R. Menopause - specific questionnaire assessment in US population-based study shows negative impact on health related quality of life. Maturitas. 2009;62(2):153-159.

26. Chen Y, Lin S, Wei Y, Gao H, Wang S, Wu Z. Impact of menopause on quality of life in community-based women in China. Menopause. 2008;15(1):144-149.

27. Satob T, Ohashi K. Quality of life assessment in community-dwelling, middle aged, healthy women in Jaban. Climacteric. 2005;8:146-153.

28. Ohen J, Cohen P, West SG, Aiken LS. Applied Multiple Regression/ Correlation Analysis for the Behavioral Sciences. 3rd ed. Mahwah, NJ: Lawrence Earlbaum Associates; 2003.

29. Cohen J. Statistical Power Analysis for the Behavioral Sciences. 2nd ed. Hillsdale, NJ: Lawrence Earlbaum Associates; 1988.

30. Heinemann K, Ruebig A, Potthoff P, et al. The Menopause Rating Scale (MRS): a methodological review. Health Qual Life Outcomes. 2004; $2: 45$.

31. Heinemann L, Potthoff P, Schneider HPG. International version of Menopause Rating Scale. Health Qual Outcomes. 2003;1:28.

32. Schneider HPG. The quality of life in the post-menopausal women. Best Pract Res Clin Obstet Gynaecol. 2002;16(3):395-409.

33. Freeman E, Sherif K. Prevalence of hot flushes and night sweats around the world: a systematic review. Climacteric. 2007;10:197-214.

34. Sievert LL, Flanagan EK. Geographical distribution of hot flash frequencies: considering climatic influences. Am J Phys Anthropol. 2005; 128(2):437-443.

35. Green R, Santoro N. Menopausal symptoms and ethnicity: the study of Women's Health across the Nation. Women Health (Lond Engl). 2009; 5(2):127-133.

36. Avis NE, Stellato R, Crawford S, et al. Is there a menopausal syndrome? Menopausal status and symptoms across racial/ethnic groups. Soc Sci Med. 2001;52(3):345-356.

37. GOLD EB, Sternfeld B, Kelsey JL, et al. Realtion of demographic and lifestyle factors to symptoms in a multi - racial/ethnic population of women in 40-55 years of age. Am J Epidemiol. 2000;152(5): 463-473.

38. Nagata C, Takatsuka N, Kawakami N, Shimizu H. Soy product intake and hot flashes in Japanese women: results from a community - bases prospective study. Am J Epidemiol. 2001;153(8):790-793.

39. Gharabibeh M, Al-obeisat S, Hattab J. Severity of menopausal symptoms of Jordanian women. Climacteric. 2009;3:1-11.

40. Chedraui P, Aguirre A, Hidalgo L, Fayad L. Assessing menopausal symptoms among healthy middle aged women with Menopause Rating Scale. Maturitas. 2007;56:271-278.

41. Mikkelsen T, Graff-Iverson S, Sundby J, Bjertness E. Early menopause, association with tobacco smoking, coffee consumption and other lifestyle factors: a cross-sectional study. BMC Public Health. 2007; $7: 149$

42. Palmer JR, Rosenberg L, Wise LA, Horton N, Campell A. Onset of natural menopause in African American Women. Am J Public Health. 2003;93(2):299-306.

43. Parazzini F. Determinants of age at menopause in women attending menopause clinic in Italy. Maturiats. 2007;56:280-287. 
International Journal of Women's Health

Dovepress

\section{Publish your work in this journal}

The International Journal of Women's Health is an international, peerreviewed open-access journal publishing original research, reports, editorials, reviews and commentaries on all aspects of women's healthcare including gynecology, obstetrics, and breast cancer. The manuscript management system is completely online and includes

Submit your manuscript here: http://www.dovepress.com/international-journal-of-womens-health-journa a very quick and fair peer-review system, which is all easy to use. Visit http://www.dovepress.com/testimonials.php to read real quotes from published authors. 